\title{
NATURAL CONVECTION OF WATER-CU NANOFLUID IN A POROUS CAVITY WITH TWO PAIRS OF HEAT SOURCE-SINK AND MAGNETIC EFFECT
}

\author{
L. JINO, A. VANAV KUMAR*
}

Department of Basic and Applied Science, National Institute of Technology Arunachal Pradesh, Arunachal Pradesh, India

\begin{abstract}
A numerical study of flow behaviour in a cavity due the natural convection and applied magnetic field is carried out. The heat transfer from the heated boundary and the flow patterns are derived by using the governing equations which are non-dimensionalized and solvedusing the FDM (Finite Difference Method). The flow patterns are visualized by streamlines and isotherms for different values of non dimensional parameters Ra, Da, $\phi, H a$. Resuction in streamlinevelocityoccurs for increase in $\phi, \mathrm{Ha}$ and with decrease in $\mathrm{Da}$. The heat transfer from the source/sink from the bottom of the cavity is described using the average Nusselt number.
\end{abstract}

KEYWORDS: Porous Cavity, Natural Convection, Magnetic Field, Nanofluid, Source/Sink

Received: Jun 08, 2020; Accepted: Jun 28, 2020; Published: Sep 22, 2020; Paper Id.: IJMPERDJUN20201378

\section{INTRODUCTION}

Study of fluid flow through a porous matrix have an application in variousfieldsuch as crystalgrowth, phase change progress, manufacturing, geothermal extraction, contaminant transport, etc. (Bejan (2006); Dullien(1979); Ingham et al. (2004)). There has been lot of study of fluid flow inside an square cavity. Variousphysical conditions have been incorporated and investigated for flows inside square cavity.

Saeid (2005)discussed the heat and flow field due to natural convection in a porousrectangular enclosure heatedpartially at the bottomwall. The length of the heat source and Rayleigh number signifies the heattransfer rate. Basak et al. (2006)analysed the natural convective effect of various thermal boundaries in square cavityfill up with the porous medium. The analysis shows thatheattransfer and flow circulation intensitygetincreased for increasing the Darcy number. Balla et al. (2017)discussed the effect of differentnanoparticles in MHD free convection. Mehmood et al. (2017)examined the inclination of magneticfield on natural convection in an aluminawater filledporouscavity. Sheikholeslami (2017)didanalysis on MHD natural convection in a open cavity in a porous media. some of the findingsquotethat, an increase in flow intensity and the shape of flow fieldchanged for increase in the Darcy number. Gorla et al. (2017)reported the result of MHD natural convective effect in a cavity at porous media heated and cooledwith the source/sink. The results reports, the magnitude of flow velocity and Nusselt numberreduces for increase in the Hartmann number and solid volume fraction. Sureshkumar et al. (2018)discussed the inclination of magneticfield in a top liddriven square porouscavityfilledwith nanofluid. Mansour et al. (2018)analysed the effect of MHD natural convection, heated sources on both the horizontal boundaries and cooled cold sink on both the vertical boundaries in a porouscavityfiledwith the $\mathrm{Al}_{2} \mathrm{O}_{3}$-water-Cu hybrid nanofluid. Abdulkadhim et al. (2018)discussed the conjugateheattransfer in a porouscavitypartiallyheated on leftwallboundary. Rashad et al. (2018)discussed the effect of magneticfield, natural convection, and location \& 
size of source/sink pair on the horizontal wall of the $\mathrm{Cu}$-water nanofluid porouscavity. The best location and size of the source/sinkisfound in theirstudy and itisnotedthatdecrease in Nusselt number for increase in Hartmann number and solid volume fraction. Kumar et al. (2019)investigated flow field on non-uniformboundary conditions in $\mathrm{Cu}$-water filledporouscavity. Vo et al. (2019)analyzed the effect of variation in shape of the nanoparticles, magneticfield, Rayleigh number, radiation parameter on nanofluid filledsinusoidalshapedcavity. Muthukumar et al. (2019)disussedinclinedmagneticfieldeffect on mixed convection porouscavity. Babazadeh et al. (2020)studied the flow behaviour of hybrid nanofluid on porouscavity due to radiation and magneticfieldeffect.

Yaghoubi Emami et al. (2018)discussed the inclination of cavity and location of heater configuration on cu-water nanofluid porouscavity. Sheremet et al. (2015)investigatedTiwari and Das model of nanofluid in saturatedporouscavity. Mahmoodi et al. (2015)reportedvarious cases for heattransfer due to natural convection at locating the source, sink pair at differentwall in a cavityfill up with the liquid gallium. Groşan et al. (2015)presented the free convection effect on nanofluid filledcavity by consideringBrownian and thermophoreticeffects. The work express that, nanoparticle concentration distribution islessnear the heatedwallthan the cold one. Teamah and El-Maghlany (2012)presentedheatgeneration, heat absorption and magneticfieldeffect in a nanofluid filledcavity. Aminossadati and Ghasemi (2011)discussed the flow patterns and heattransfer due to two pairs of source and sink pairs in the bottom of the cavityfilledwith the $\mathrm{CuO}$ /water nanofluid. Ghasemi et al. (2011) have studied the effect of variation of Hartmann number due to natural convection in an $\mathrm{Al}_{2} \mathrm{O}_{3}$-water nanofluid cavity. Sathiyamoorthy and Chamkha (2010)studied the linearlyheatedboundaryeffect on natural convection and magneticfield in a cavityfilledwith the liquid gallium. Aminossadati and Ghasemi (2009)presented flow patterns and heattransfer of variousnanofluids in partiallyheatedbottomcavitywithconsideringmagneticfieldeffects. Mahmoodi et al. (2015)discussed the effect of location of source/sink on variousboundariesundermagneticfield. Rudraiah et al. (1995); Wilkes and Churchill (1966) have implemented the discretization and equationsolvingprocedure for fluid flow in a cavityusing the finitedifferencemethod.

\section{PROBLEM DEFINITION}

A square cavity of dimension $H \times H$ filledwith the $\mathrm{Cu}$-water nanofluid isshown in Figure 1 . The two pairs of heat sourcesink cover the entirelength of the bottomwalldeployed as sink and source from the origin of the cavity and remaining all the walls are insulated. The heat source $\left(T_{h}\right)$ ismaintained a constant temperaturehigherthan the heatsink $\left(T_{c}\right)$. The nanofluid isassumed to be a laminar, Newtonian, incompressible with $P r=6.2$ and other some properties of the nano particle and the base fluid are listed in the Table 1. The flow isconsidered as negligible radiation effects and the dissipation, displacementcurrents and joule heating are alsoneglected. 


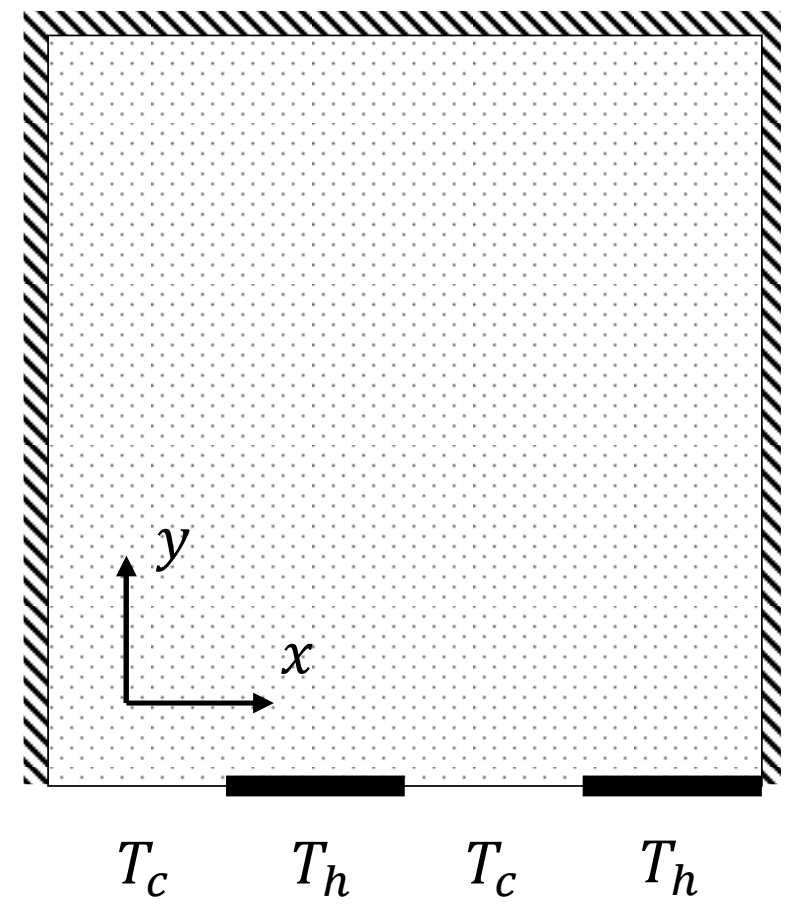

Figure 1 : Physical Model

\section{GOVERNING EQUATION}

The dimensional governing equations of continuity, momentum and energy equations for the natural convection with magnetic and porous effect in the two-dimensional square cavity can be written in dimensional forms as follows

$$
\begin{gathered}
\frac{\partial u}{\partial x}+\frac{\partial v}{\partial y}=0 \\
\rho_{n}\left[\frac{\partial u}{\partial t}+u \frac{\partial u}{\partial x}+v \frac{\partial u}{\partial y}\right]=\mu_{n}\left(\frac{\partial^{2} u}{\partial x^{2}}+\frac{\partial^{2} u}{\partial y^{2}}\right)-\frac{\partial p}{\partial x}-\rho_{n} \frac{A(1-\lambda)^{2}}{\lambda^{3}} u \\
\rho_{n}\left[\frac{\partial v}{\partial t}+u \frac{\partial v}{\partial x}+v \frac{\partial v}{\partial y}\right]=\mu_{n}\left(\frac{\partial^{2} v}{\partial x^{2}}+\frac{\partial^{2} v}{\partial y^{2}}\right)-\frac{\partial p}{\partial y}-\rho_{n} \frac{A(1-\lambda)^{2}}{\lambda^{3}} v+(\rho \beta)_{n} g\left(T-T_{r e f}\right)-\sigma_{n} B^{2} v \\
\frac{\partial T}{\partial t}+u \frac{\partial T}{\partial x}+v \frac{\partial T}{\partial y}=\alpha_{n}\left(\frac{\partial^{2} T}{\partial x^{2}}+\frac{\partial^{2} T}{\partial y^{2}}\right)
\end{gathered}
$$

By using the non-dimensionalparameters, $X=x / H, Y=y / H, \tau=\left(t \alpha_{f}\right) / H^{2}, U=H u / \alpha_{f}, V=H v / \alpha_{f}, P=$ $\left(p H^{2}\right) /\left(\rho_{n} \alpha_{f}^{2}\right), \theta=\left(T-T_{c}\right) /\left(T_{h}-T_{c}\right), D a=\mu_{f} \lambda^{3} / A(1-\lambda)^{2} H^{2}, R a=g \beta_{f} H^{3}\left(T_{h}-T_{c}\right) / v_{f} \alpha_{f}, \operatorname{Pr}=v_{f} / \alpha_{f}, H a=$ $B H \sqrt{\sigma_{n} /\left(\rho_{n} v_{n}\right)}$,

The final partial differentialequationsobtainedfromdimensionalgoverningequations (1-4) is,

$$
\frac{\partial U}{\partial X}+\frac{\partial V}{\partial Y}=0
$$




$$
\begin{gathered}
\frac{\partial U}{\partial \tau}+U \frac{\partial U}{\partial X}+V \frac{\partial U}{\partial Y}=\frac{\mu_{n}}{\rho_{n} \alpha_{f l}}\left(\frac{\partial^{2} U}{\partial X^{2}}+\frac{\partial^{2} U}{\partial Y^{2}}\right)-\frac{\partial P}{\partial X}-\rho_{f l} \frac{P r}{D a} U \\
\frac{\partial V}{\partial \tau}+U \frac{\partial V}{\partial X}+V \frac{\partial V}{\partial Y}=\frac{\mu_{n}}{\rho_{n} \alpha_{f l}}\left(\frac{\partial^{2} V}{\partial X^{2}}+\frac{\partial^{2} V}{\partial Y^{2}}\right)-\frac{\partial P}{\partial Y}-\rho_{f l} \frac{P r}{D a} V+\frac{(\rho \beta)_{n}}{\rho_{n} \beta_{f l}} \operatorname{RaPr}(\theta)-H a^{2} \operatorname{Pr}(V) \\
\frac{\partial \theta}{\partial \tau}+U \frac{\partial \theta}{\partial X}+V \frac{\partial \theta}{\partial Y}=\frac{\alpha_{n}}{\alpha_{f l}}\left(\frac{\partial^{2} \theta}{\partial X^{2}}+\frac{\partial^{2} \theta}{\partial Y^{2}}\right)
\end{gathered}
$$

The thermophysical and transport properties of the colloid vary with the volume fraction $(\phi)$ of the particles. Colloid's density, heat capacities and part of the Boussinesq terms are calculated from the mixture relation:

$$
\begin{gathered}
\mu_{n}=\mu_{f l} /\left(1-\phi_{0}\right)^{2.5} \\
\rho_{n}=\left(1-\phi_{0}\right) \rho_{f l}+\phi_{0} \rho_{p} \\
\left(\rho c_{p}\right)_{n}=\left(1-\phi_{0}\right)\left(\rho c_{p}\right)_{f l}+\phi_{0}\left(\rho c_{p}\right)_{p} \\
(\rho \beta)_{n}=\left(1-\phi_{0}\right)(\rho \beta)_{f l}+\phi_{0}(\rho \beta)_{p} \\
k_{n}=k_{f l}\left[\left[k_{p}+2 k_{f l}-2 \phi_{0}\left(k_{f l}-k_{p}\right)\right] /\left[k_{p}+2 k_{f l}-2 \phi_{0}\left(k_{f l}-k_{p}\right)\right]\right]
\end{gathered}
$$

The governing equations (5-8) with the nanofluid properties are solved using the boundary conditions as,

$$
\left.\begin{array}{c}
\text { onverticalwalls: } u=v=0, \partial \theta / \partial X=0 \\
\text { ontopwall: } u=v=0, \partial \theta / \partial Y=0 \\
\text { onbottomwall: } u=v=0, \theta=1 \text { (onthesource) } \\
\theta=0 \text { (onthesink) }
\end{array}\right\}
$$

Table 1 : Properties of base fluid and particle

\begin{tabular}{|c|c|c|}
\hline & Water & Cu Nanoparticles \\
\hline$\rho$ & $997.1 \mathrm{~kg} / \mathrm{m}^{3}$ & $8954 \mathrm{~kg} / \mathrm{m}^{3}$ \\
\hline$\mu$ & $8.9 \times 10^{-4} \mathrm{Pas}$ & - \\
\hline$c_{p}$ & $4179 \mathrm{~J} / \mathrm{kgK}$ & $383 \mathrm{~J} / \mathrm{kgK}$ \\
\hline$k$ & $0.6 \mathrm{~W} / \mathrm{mK}$ & $400 \mathrm{~W} / \mathrm{mK}$ \\
\hline$\beta$ & $2.1 \times 10^{-4} \mathrm{k}^{-1}$ & $1.67 \times 10^{-5} \mathrm{k}^{-1}$ \\
\hline
\end{tabular}

Heat transfer and averaged heat transfer from the boundary is pronounced as local Nusselt number and averaged Nusselt number.

$$
\begin{aligned}
& N u_{m}=-k_{n} / k_{f l}(\partial T / \partial Y) \\
& N u=\int_{\text {onheatsources }} N u_{m} d X
\end{aligned}
$$

Integrating the local Nusselt number along the length of the heat source gives the average Nusselt number. Therefore, the total heat transfer of a cavity from the source is the sum of the average numbers of the two heat sources.

\section{NUMERICAL APPROACH AND VALIDATION OF WORK}


The dimensionless governing equation (5-8) is transformed into the Streamfunction-Vorticity approach and discretized using the Finite Difference technique. A suitable square domain is made with equal grid spacing of $150 \times 150$ on either direction and the system is numerically modelled in FORTRAN. The solution makes use of an iterative process that is repeated till maximum residual of grid is below $10^{-5}$.The present computational work is validated with the standard published results. Figure 2 presents the validation of current study (coloured) against streamlines and isotherms for a. Aminossadati and Ghasemi (2011) and $b$. Ghasemi et al. (2011).
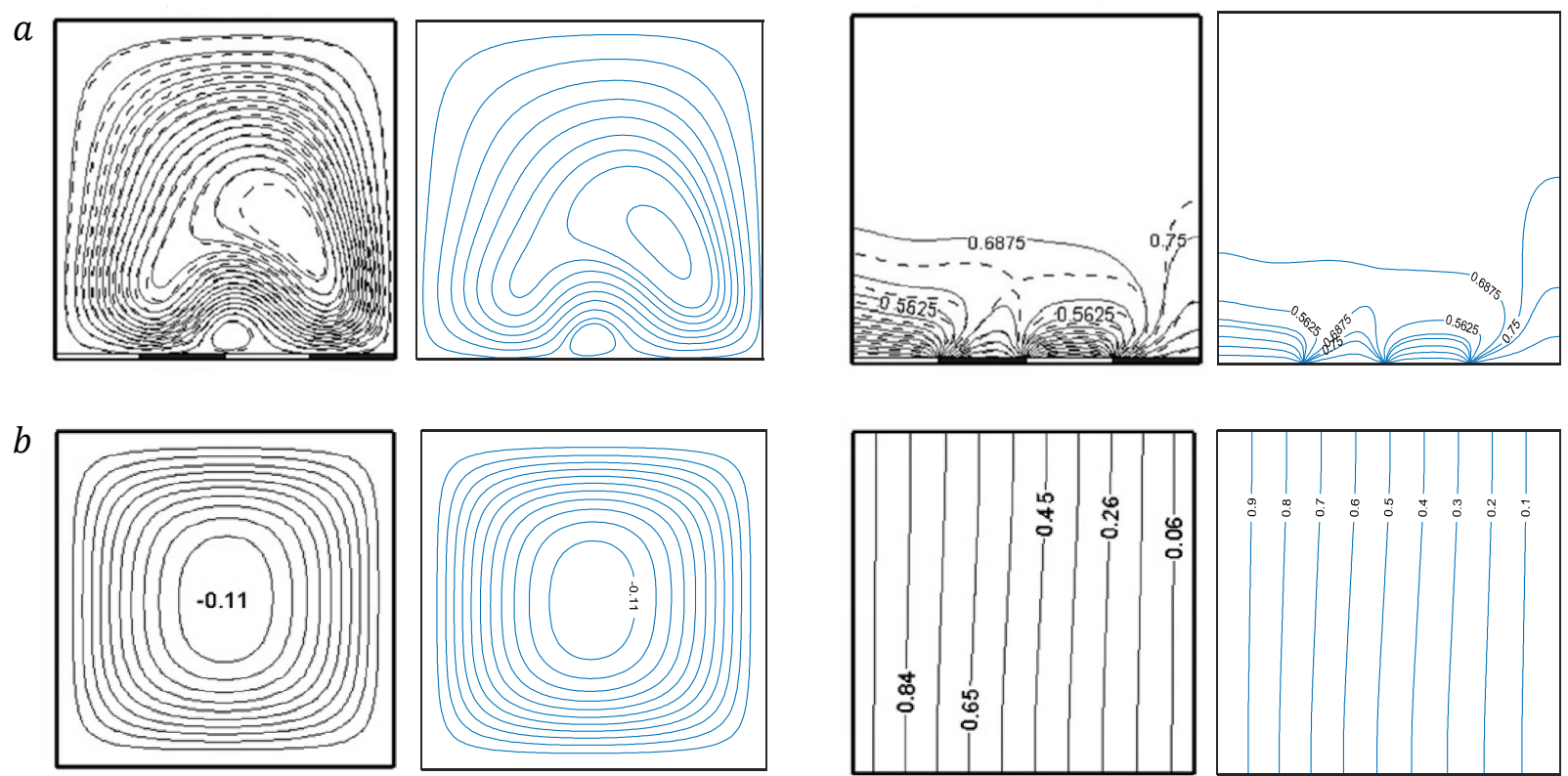

Figure 2 : Validation withwork by Aminossadati and Ghasemi (2011); Ghasemi et al. (2011)

\section{RESULTS AND DISCUSSIONS}

The fluid flow by streamlines and isotherms are presented for the fixed Prandtl number $(\operatorname{Pr}=6.2)$ and various Rayleigh number $\left(R a=10^{3}, 10^{4}, 10^{5}\right)$, Darcy number $\left(D a=10^{-2}, 10^{2}\right)$, volume fraction $(\phi=0.01,0.05,0.1)$ and Hartmann number $(H a=0,50)$.

Figure 3 shows the streamline flow patterns for $\phi=0.01, D a=10^{-2}, H a=0,50$ and $R a=10^{4}, 10^{5}, 10^{6}$. Variation in $R a$ towards the right demonstrates the growth of outer two circulations and domination of middle circulation over the increment in the buoyancy driven effect. Along with the growth, circulation intensity also get stronger due to the applicable convective effect. It isnotedthat at the bottom of figure, reduction in the flow intensity for increase in $\mathrm{Ha}$.

Similarlyisotherm flow patterns for various values of $R a$ and $H a$ at $\phi=0.01$ and $D a=10^{-2}$ isshown in Figure 4 . Temperature distribution ratio is more in the cavity for increase in the $R a$. Here at lower $D a$, less effect is found in the $\mathrm{Ha}$ because of the domination of conduction over the convection. 

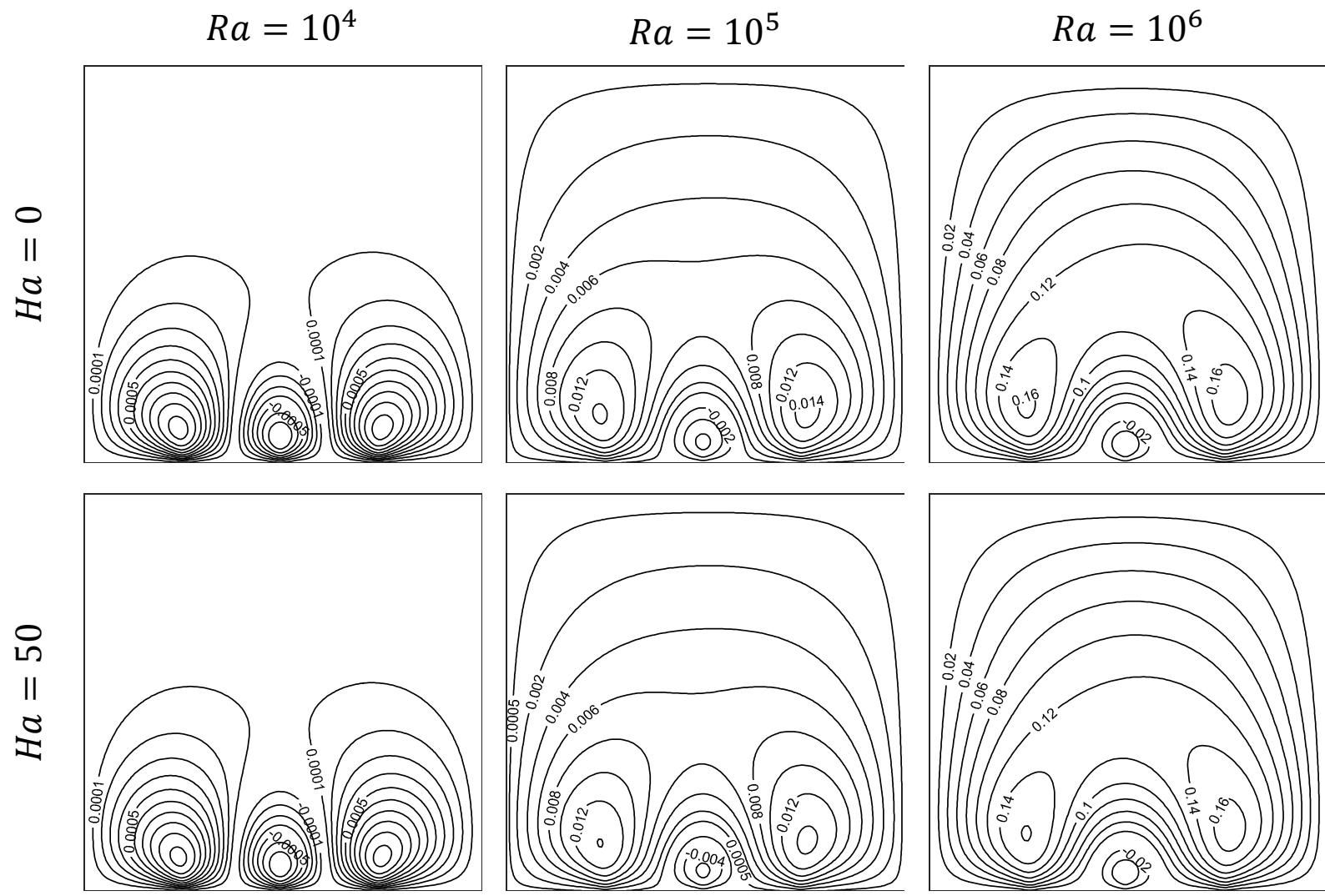

Figure 3 : Streamlines contour for different values of $\mathrm{Ra}, \mathrm{Ha}$ at $\mathrm{Da}=10^{-2}$ and $\phi=0.01$
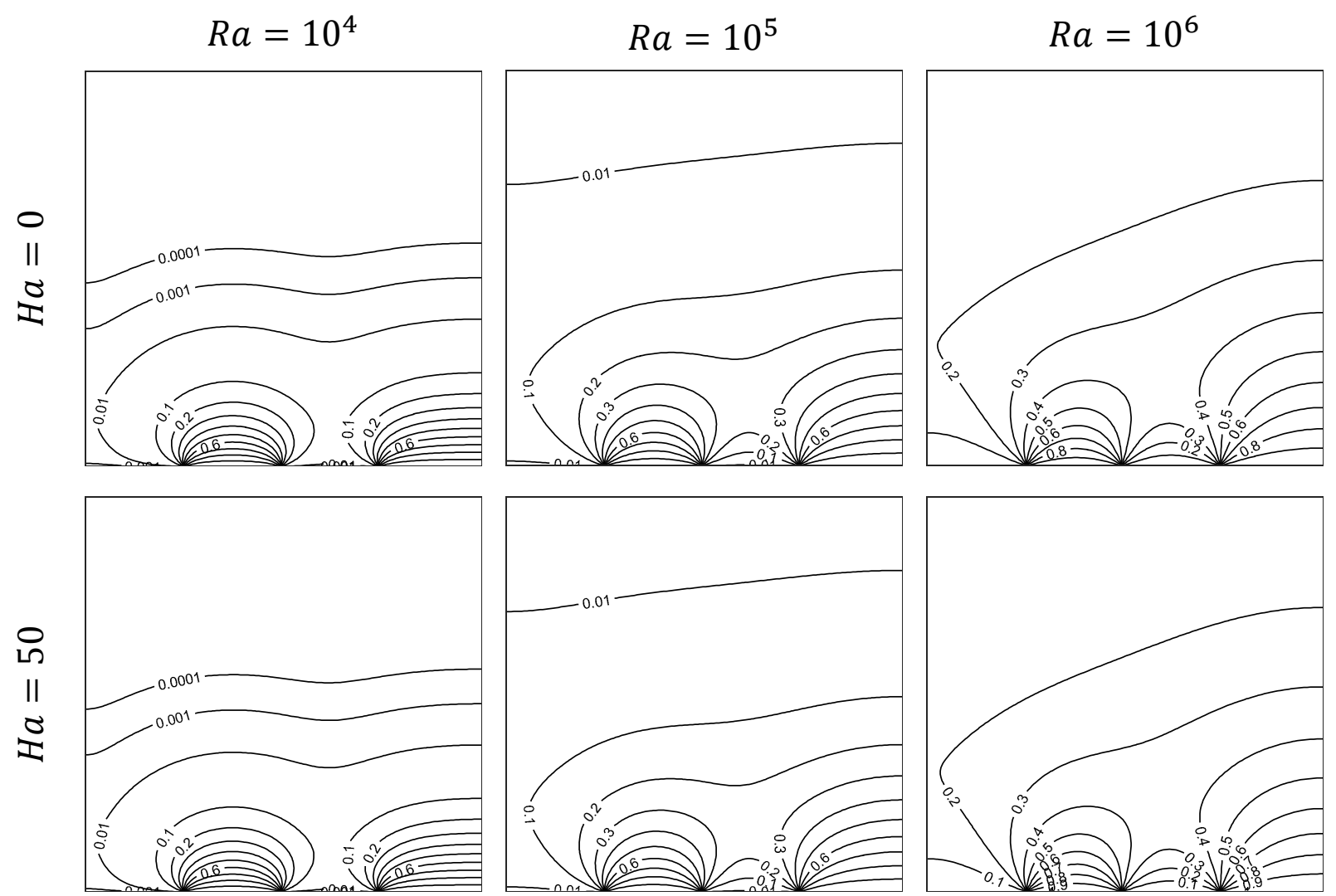

Figure 4 : Isotherms contour for different values of $\mathrm{Ra}, \mathrm{Ha}$ at $\mathrm{Da}=10^{-2}$ and $\phi=0.01$ 

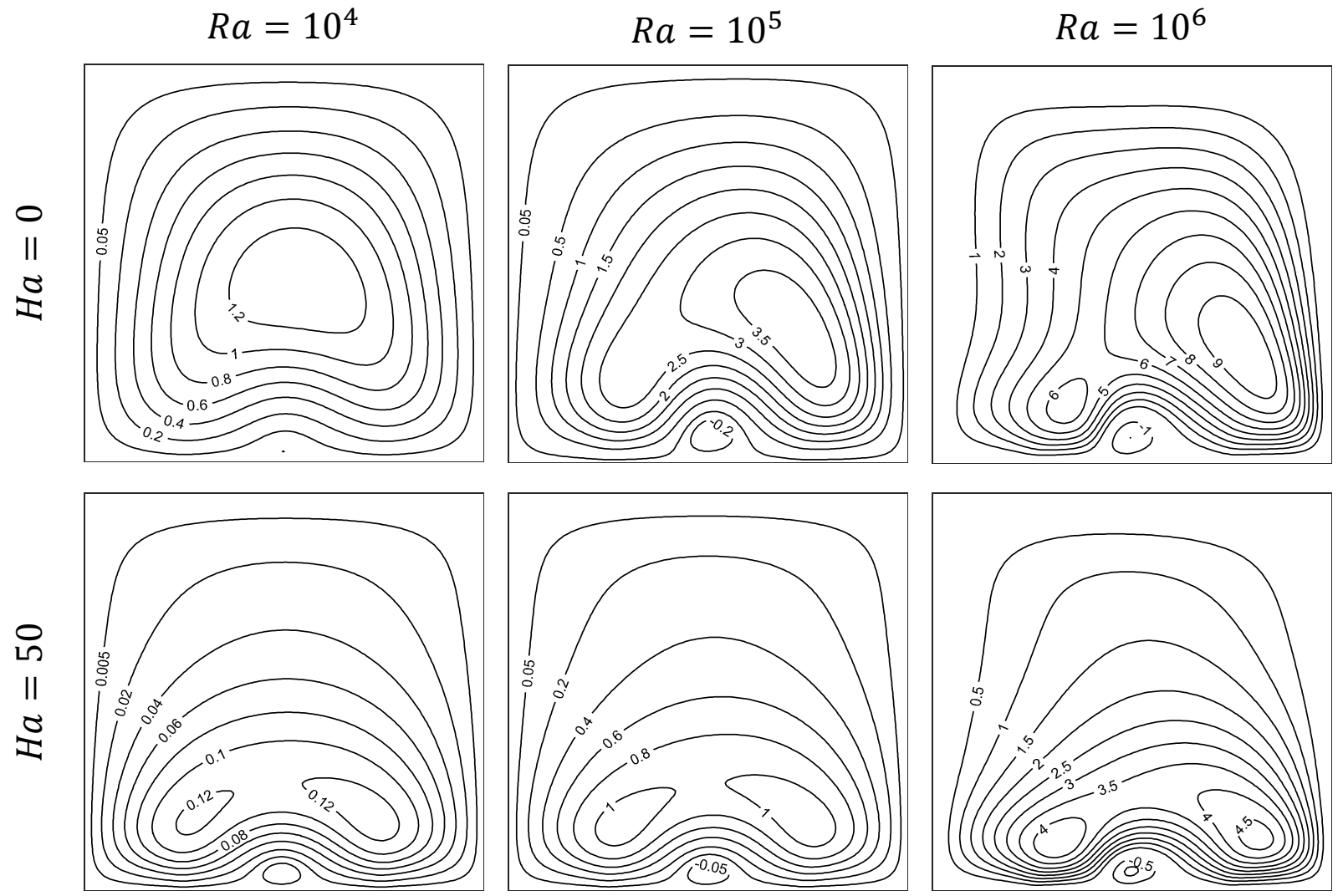

Figure 5 : Streamlines contour for different values of $\mathrm{Ra}, \mathrm{Ha}$ at $\mathrm{Da}=10^{2}$ and $\phi=0.01$
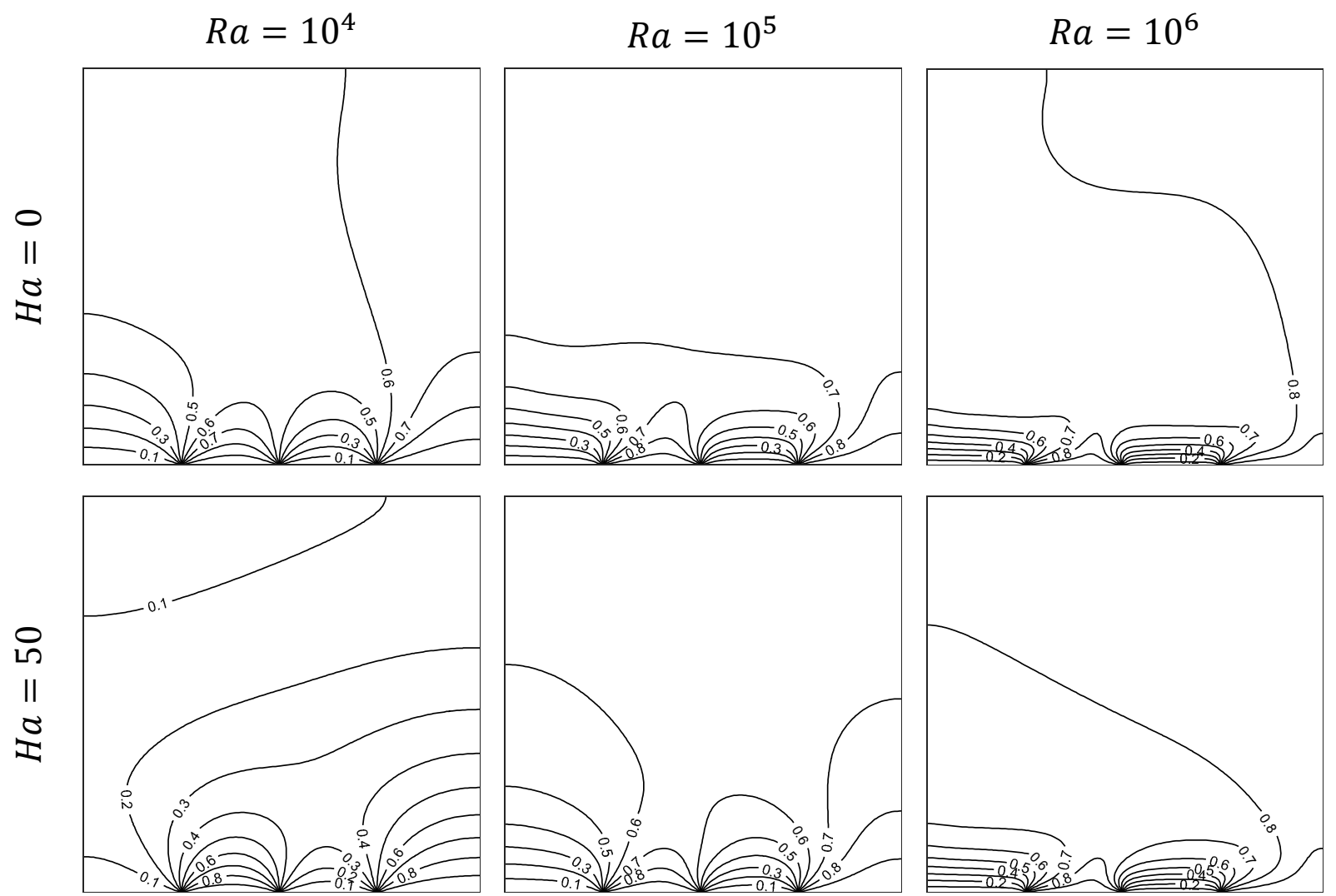

Figure 6 : Isotherms contour for different values of $\mathrm{Ra}, \mathrm{Ha}$ at $\mathrm{Da}=10^{2}$ and $\phi=0.01$ 
An increase in fluid flow intensity is observed in case of increasing the $D a=10^{-2}$ to $D a=10^{2}$ as demonstrated in the Figure 5. The reason for increased flow rush is due to the increase in the permeability level in the cavity. In this case, multiplication of velocity intensity is occurs compared to lower $D a$ and merging of two outer most circulation at $R a=$ $10^{4}$. Later increase in $R a$ at higher Darcy number causes separation in circulation and also growth in circulation intensity. The discontinued heating in the bottom wall causes the oppositely directed middle circulation. It is observed that dominance of magnetic field is increased for $D a=10^{2}$ as flow velocity get decreased for increase in $\mathrm{Ha}$.

Figure 6 shows the isotherms for various values of $R a$ and $H a$ for $D a=10^{2}, \phi=0.01$. More temperature distribution is found as compared to the lower $D a$. Temperature distribution level is raised in case of increased $R a$ due to the raise in the behaviour of convection. The distribution of temperature is affected for increase in the $\mathrm{Ha}$.

The streamlines and isotherms profile for various values of $\phi$ at $D a=10^{-2}, H a=50$ and $R a=10^{6}$ is illustrated in the Figure 7. The maximum value of the streamline $(\psi=0.16)$ reduces to $(\psi=0.1)$ for the increase in the $\phi=0.01$ to $\phi=0.1$. The same sinerio is found for increase in $D a$ to $10^{2}$ as shown in Figure 8 . This reduction in the flow intensity is due to the raise in viscosity as increase in the nano particle concentration. The viscosity is the responsible for the behaviour of flow resistance in the cavity.
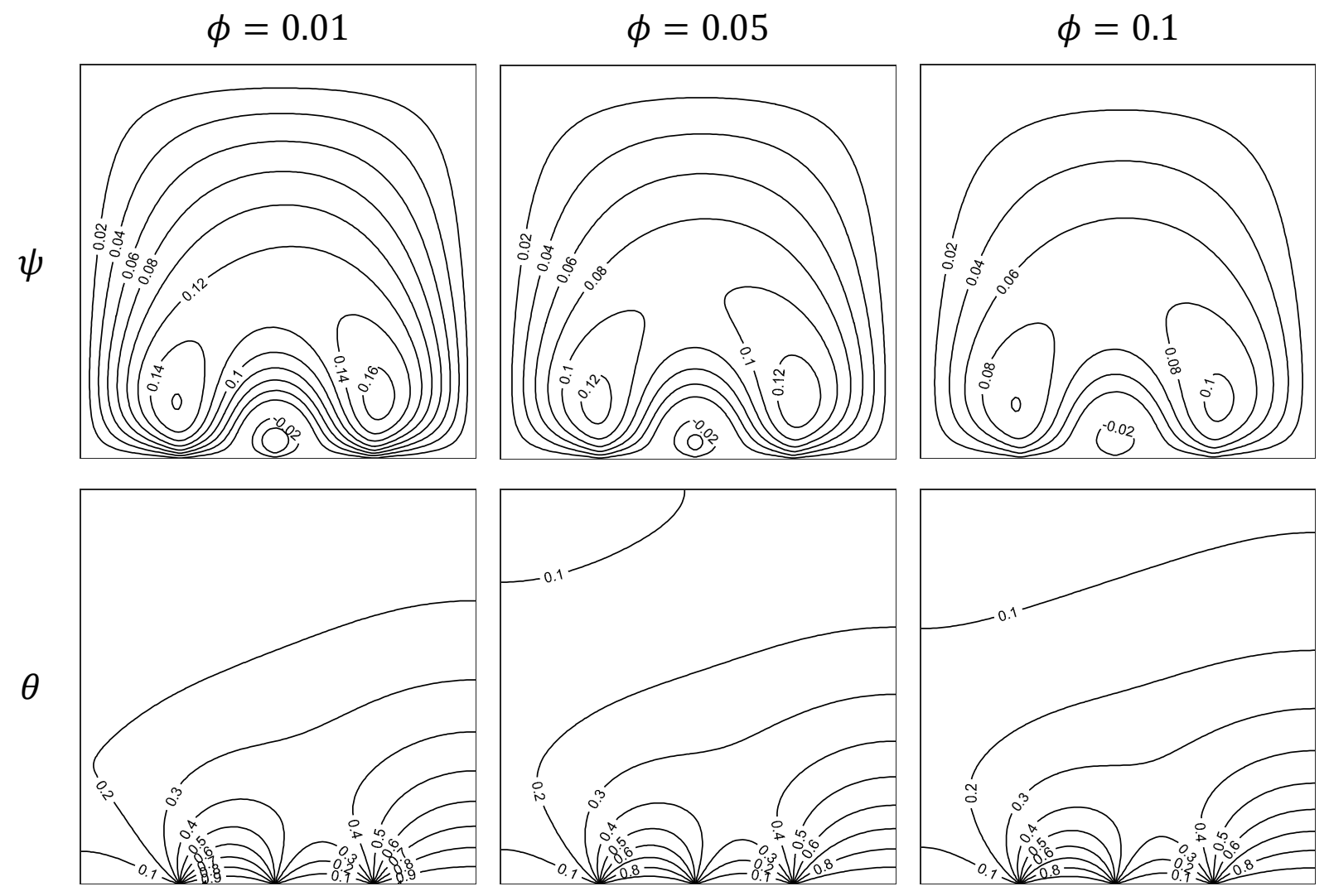

Figure 7 : Streamlines $(\psi)$, Isotherm $(\theta)$ contour for different values of $\phi$ at $D a=10^{-2}, R a=10^{6}$ and $H a=50$ 

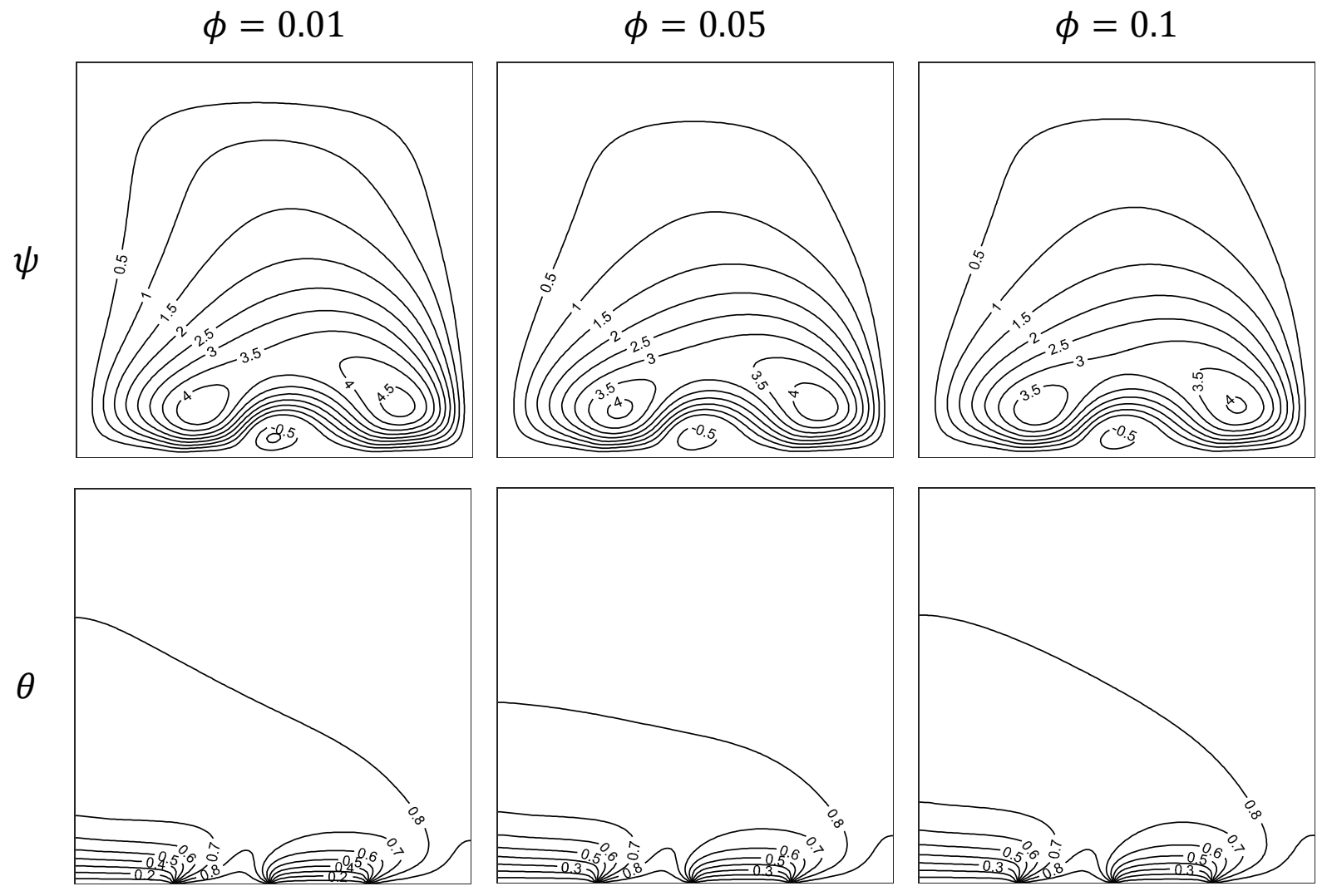

Figure 8 : Streamlines $(\psi)$, Isotherm $(\theta)$ contour for different values of $\phi$ at $D a=10^{2}, R a=10^{6}$ and $H a=50$

Average Nusselt number from the bottom wall of the cavity is show in the Figure 9 and Figure 10. Reduction in the $N u$ is observed for increase in $R a$ for the case of $D a=10^{-2}$ and increase in the $N u$ is found in the case of $D a=10^{2}$. At lower $D a$, the $N u$ decreases due to reduction in the conduction dominance over the increase in the $R a$. For increase in the $D a$ leads to increase in the permeability causes to fluid flow freely and domination of convection get significance over the higher $R a$. The detailed view about the effect of solid volume fraction is shown in Figure 10. The advantage of heat transfer property of nano particle leads to increase in the $N u$ for increase in the $\phi$, which is applicable for lower and higher $\mathrm{Da}$. The resistance in heat transfer for applying the magnetic field can be reviewed increasing the $\mathrm{Ha}$.

$a$

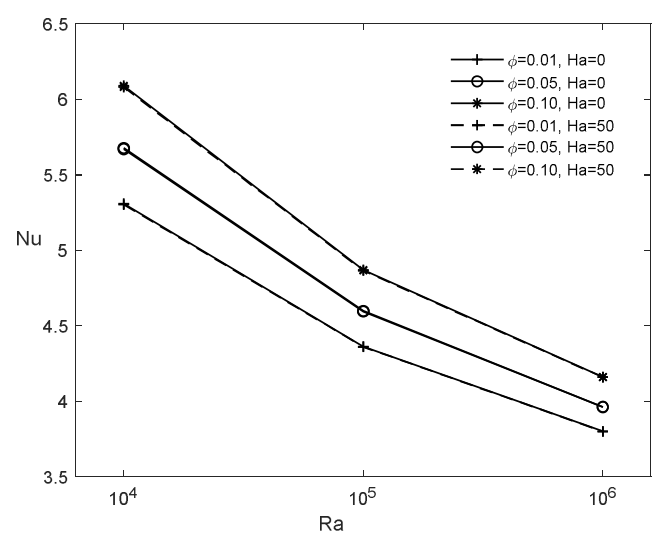

$b$

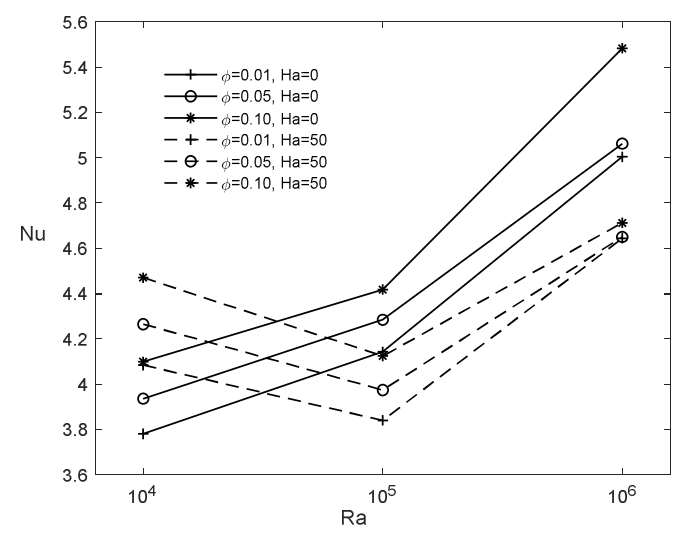

Figure 9 : Average Nusselt number $(\mathrm{Nu})$ for different values of $\phi, \mathrm{Ra}, \mathrm{Ha}$ 
$a$

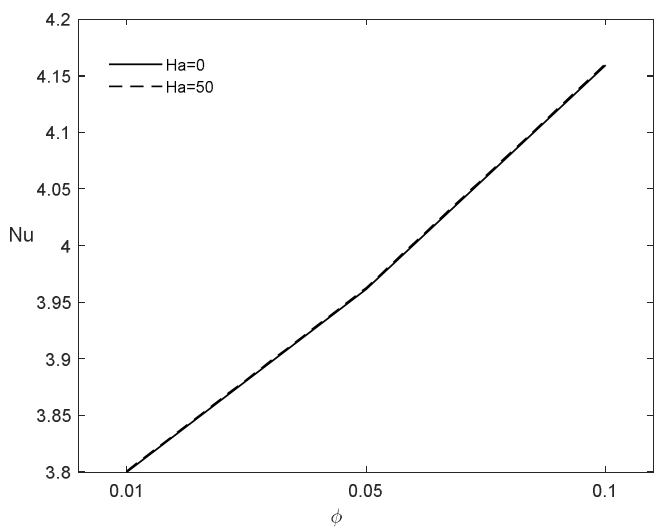

$b$

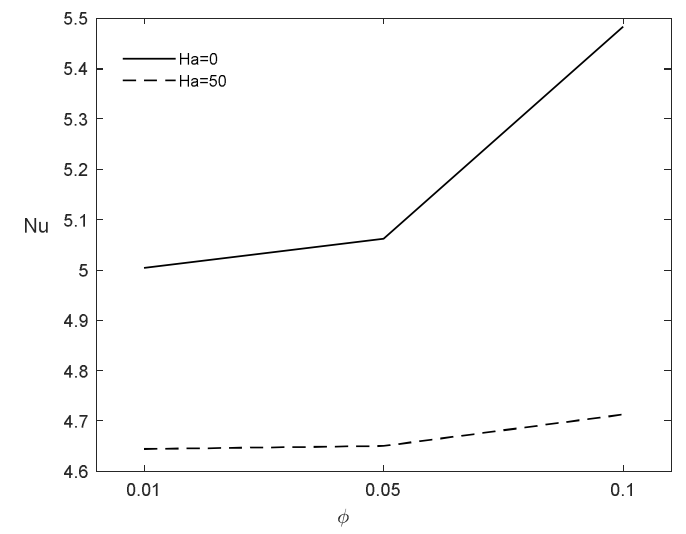

Figure 10 : Average Nusselt number $(\mathrm{Nu})$ for different values of $\phi, \mathrm{Ha}$ and $\mathrm{Ra}=10^{6}$

\section{CONCLUSIONS}

In this paper, the discussion about the flow field and the heat transfer for the square porous cavity with two pairs of source/sink at the bottom of the wall. Some of the important results are,

- The effect of $\mathrm{Ha}$ is more significant in the case of higher $\mathrm{Da}$.

- The flow velocity intensity gets increased for the higher $D a$ and $R a$.

- An increase in the solid volume fraction of nano particle causes the decrease in the flow intensity and increases $\mathrm{Nu}$.

- The domination of natural convective effect is more applicable in the case of higher $D a$.

- An increase in the magnetic field effect $(\mathrm{Ha})$ causes the reduction in the flow velocity and heat transfer rate.

\section{ACKNOWLEDGEMENTS}

The first author acknowledges the partial financial support through TEQIP-III Project, NIT Arunachal Pradesh.

The authors acknowledge the support through DST project. Sanction number : SERB ECR/2017/001007.

\section{REFERENCES}

1. Abdulkadhim, A., Abed, A. M., \& Al-Farhany, K. (2018). Computational investigation of conjugate heat transfer in cavity filled with saturated porous media. Frontiers in Heat and Mass Transfer, 11. https://doi.org/10.5098/hmt.11.12

2. Aminossadati, S. M., \& Ghasemi, B. (2009). Natural convection cooling of a localised heat source at the bottom of a nanofluid-filled enclosure. European Journal of Mechanics, B/Fluids, 28(5), 630-640. https://doi.org/10.1016/j.euromechflu.2009.05.006

3. Aminossadati, S. M., \& Ghasemi, B. (2011). Natural convection of water-CuO nano fluid in a cavity with two pairs of heat source - sink. International Communications in Heat and Mass Transfer, 38(5), 672-678. https://doi.org/10.1016/j.icheatmasstransfer.2011.03.013

4. Babazadeh, H., Shah, Z., Ullah, I., Kumam, P., \& Shafee, A. (2020). Analysis of hybrid nanofluid behavior within a porous cavity including Lorentz forces and radiation impacts. Journal of Thermal Analysis and Calorimetry, 0123456789. 
https://doi.org/10.1007/s10973-020-09416-1

5. Balla, C. S., Kishan, N., Gorla, R. S. R., \& Gireesha, B. J. (2017). MHD boundary layer flow and heat transfer in an inclined porous square cavity filled with nanofluids. Ain Shams Engineering Journal, 8(2), 237-254. https://doi.org/10.1016/j.asej.2016.02.010

6. Basak, T., Roy, S., Paul, T., \& Pop, I. (2006). Natural convection in a square cavity filled with a porous medium: Effects of various thermal boundary conditions. International Journal of Heat and Mass Transfer, 49(7-8), $1430-1441$. https://doi.org/10.1016/j.ijheatmasstransfer.2005.09.018

7. Bejan, A. (2006). Convection in Porous Media. In Convection in Porous Media. https://doi.org/10.1007/0-387-33431-9

8. Dullien, F. A. (1979). Porous media: fluid transport and pore structure. (Second Edi). Academic press.

9. Ghasemi, B., Aminossadati, S. M., \& Raisi, A. (2011). Magnetic field effect on natural convection in a nanofluid-filled square enclosure. International Journal of Thermal Sciences, 50(9), 1748-1756. https://doi.org/10.1016/j.ijthermalsci.2011.04.010

10. Gorla, R. S. R., Siddiqa, S., Mansour, M. A., Rashad, A. M., \& Salah, T. (2017). Heat source/sink effects on a hybrid nanofluid-filled porous cavity. Journal of Thermophysics and Heat Transfer, 31(4), 847-857. https://doi.org/10.2514/1.T5085

11. Groşan, T., Revnic, C., Pop, I., \& Ingham, D. B. (2015). Free convection heat transfer in a square cavity filled with a porous medium saturated by a nanofluid. International Journal of Heat and Mass Transfer, 87, 36-41. https://doi.org/10.1016/j.ijheatmasstransfer.2015.03.078

12. Ingham, D. B., Bejan, A., Mamut, E., \& Pop, I. (2004). Emerging Technologies and Techniques in Porous Media. In Emerging Technologies and Techniques in Porous Media (Vol. 134). Springer Science \& Business Media. https://doi.org/10.1007/97894-007-0971-3

13. Kumar, A. V., Jino, L., Berlin, M., \& Mohanty, P. K. (2019). Magnetic field effect on nanofluid suspension cavity by nonuniform boundary conditions. AIP Conference Proceedings, 2134(August). https://doi.org/10.1063/1.5120205

14. Mahmoodi, M., Hemmat, M., \& Akbari, M. (2015). Magneto-natural convection in square cavities with a source-sink pair on different walls. 47, 21-32. https://doi.org/10.3233/JAE-130097

15. Mansour, M. A., Siddiqa, S., Gorla, R. S. R., \& Rashad, A. M. (2018). Effects of heat source and sink on entropy generation and MHD natural convection of Al2O3-Cu/water hybrid nanofluid filled with square porous cavity. Thermal Science and Engineering Progress, 6(April 2017), 57-71. https://doi.org/10.1016/j.tsep.2017.10.014

16. Mehmood, K., Hussain, S., \& Sagheer, M. (2017). Numerical simulation of MHD mixed convection in alumina-water nanofluid filled square porous cavity using KKL model: Effects of non-linear thermal radiation and inclined magnetic field. Journal of Molecular Liquids, 238, 485-498. https://doi.org/10.1016/j.molliq.2017.05.019

17. Muthukumar, S., Prem, E., \& Suresh Kumar, S. (2019). Mixed convective heat transfer in a rectangular nanofluid filled cavity with inclined magnetic field. International Journal of Mechanical and Production Engineering Research and Development, 9(5), 1179-1190. https://doi.org/10.24247/ijmperdoct2019104

18. Rashad, A. M., Armaghani, T., Chamkha, A. J., \& Mansour, M. A. (2018). Entropy generation and MHD natural convection of a nanofluid in an inclined square porous cavity: Effects of a heat sink and source size and location. Chinese Journal of Physics, 56(1), 193-211. https://doi.org/10.1016/j.cjph.2017.11.026

19. Rudraiah, N., Venkatachalappa, M., \& Subbaraya, C. K. (1995). Combined surface tension and buoyancy-driven convection in a rectangular open cavity in the presence of a magnetic field. 30(5), 759-770. 
20. Saeid, N. H. (2005). Natural convection in porous cavity with sinusoidal bottom wall temperature variation B. 32, $454-463$. https://doi.org/10.1016/j.icheatmasstransfer.2004.02.018

21. Sathiyamoorthy, M., \& Chamkha, A. (2010). International Journal of Thermal Sciences Effect of magnetic field on natural convection flow in a liquid gallium filled square cavity for linearly heated side wall(s). 49, 1856-1865. https://doi.org/10.1016/j.ijthermalsci.2010.04.014

22. Sheikholeslami, M. (2017). Influence of magnetic field on nanofluid free convection in an open porous cavity by means of Lattice Boltzmann method. Journal of Molecular Liquids, 234, 364-374. https://doi.org/10.1016/j.molliq.2017.03.104

23. Sheremet, M. A., Grosan, T., \& Pop, I. (2015). Free Convection in a Square Cavity Filled with a Porous Medium Saturated by Nanofluid Using Tiwari and Das' Nanofluid Model. Transport in Porous Media, 106(3), 595-610. https://doi.org/10.1007/s11242-014-0415-3

24. Sureshkumar, S., Muthukumar, S., Doh, D. H., \& Prem, E. (2018). Effects of magnetic field inclination on tilted square cavity filled with a nanofluid saturated porous medium. International Journal of Ambient Energy. https://doi.org/10.1080/01430750.2018.1537935

25. Teamah, M. A., \& El-Maghlany, W. M. (2012). Augmentation of natural convective heat transfer in square cavity by utilizing nanofluids in the presence of magnetic field and uniform heat generation/absorption. International Journal of Thermal Sciences, 58, 130-142. https://doi.org/10.1016/j.ijthermalsci.2012.02.029

26. Vo, D. D., Shah, Z., Sheikholeslami, M., Shafee, A., \& Nguyen, T. K. (2019). Numerical investigation of MHD nanomaterial convective migration and heat transfer within a sinusoidal porous cavity. Physica Scripta, 94(11). https://doi.org/10.1088/1402-4896/ab2ced

27. Wilkes, J. O., \& Churchill, S. W. (1966). The finite $\square$ difference computation of natural convection in a rectangular enclosure. AIChE Journal, 12(1), 161-166. https://doi.org/10.1002/aic.690120129

28. Yaghoubi Emami, R., Siavashi, M., \& Shahriari Moghaddam, G. (2018). The effect of inclination angle and hot wall configuration on Cu-water nanofluid natural convection inside a porous square cavity. Advanced Powder Technology, 29(3), 519-536. https://doi.org/10.1016/j.apt.2017.10.027 